\title{
Addendum: Biomass enables the transition to a carbon-negative power system across western North America
}

Daniel L. Sanchez, James H. Nelson, Josiah Johnston, Ana Mileva and Daniel M. Kammen

Nature Climate Change 5, 230-234 (2015); published online 9 February 2015; addendum published after print 2 March 2017.

The authors omitted to cite a paper ${ }^{32}$ that introduces the SWITCH optimimization model.

\section{References}

32. Fripp, M. Switch: a planning tool for power systems with large shares of intermittent renewable energy. Environ. Sci. Technol. 46, 6371-6378 (2012).

Note: Owing to technical difficulties, this Addendum was published online on 2 March 2017, whereas the print version states 1 March 2017. 